\begin{tabular}{l} 
Journal of Economics and Behavioral Studies (ISSN: 2220-6140) \\
Vol. 10, No. 6A, pp. 123-130, 2018 \\
\hline \hline
\end{tabular}

\title{
Measuring Literacy Gap in the World for Economic and Social Development: Evidence from Selected
} Countries and the Lessons Learned

\author{
Gbolahan S. Osho ${ }^{1}$, Arinola C. Ebalunode ${ }^{2}$ \\ ${ }^{1}$ Department of Management and Marketing, Prairie View A\&M University, Texas, USA \\ ${ }^{2}$ Department of Education, University of South Carolina, South Carolina, USA \\ gsosho@pvamu.edu
}

\begin{abstract}
Literacy rate is a major indicator of economic and social development, the campaign for growth and improvement in this area by several international organizations have caused significant growth in all major regions of the world. The persistent theme to these various programs is that illiteracy is nonetheless prevalent in the world and more study needed to eradicate it, thus generates a significant interest in this issue. Therefore, the primary goal of this current study is to compare five major regions in the world as classified by the World Bank in regards to the differences which exist in literacy. The study concludes that literacy rates of male and female across the regions are different for Youth literacy between the age of 15 and 24. The vast conclusion is that that there is a no significant difference in male literacy among the regions in the world except for Africa. While no significant difference in female literacy among the regions in the world.
\end{abstract}

Keywords: Literacy rate, economic and social development, gender, World Bank, and MANOVA

\section{Introduction}

Literacy is a major world development indicator, major projects and campaigns are being put in place daily to combat youth and adult illiteracy in different countries, and regions. Roser and Ortiz-Ospina (2018) stated "literacy is a key skill and a key measure of a population's education and despite improvements in literacy in the second half of the 20th century however, there is still a wide disparity between nations". Rao and Sweetman (2014) suggested that about sixty-one percent about 120 million adult illiteracy across the world are women and it has been the main emphasis for international organizations and development community. While the Adult literacy index is often used to measure the number of adults who are capable of reading and writing in given states. Literacy rate deploys indicator of economic and social development, the campaign for growth and improvement in this area by several international organizations have caused significant growth in all major regions of the world. However, there is evidence that literacy gaps still exist among these regions as seen in Figure $1 \mathrm{a}$ and $1 \mathrm{~b}$.

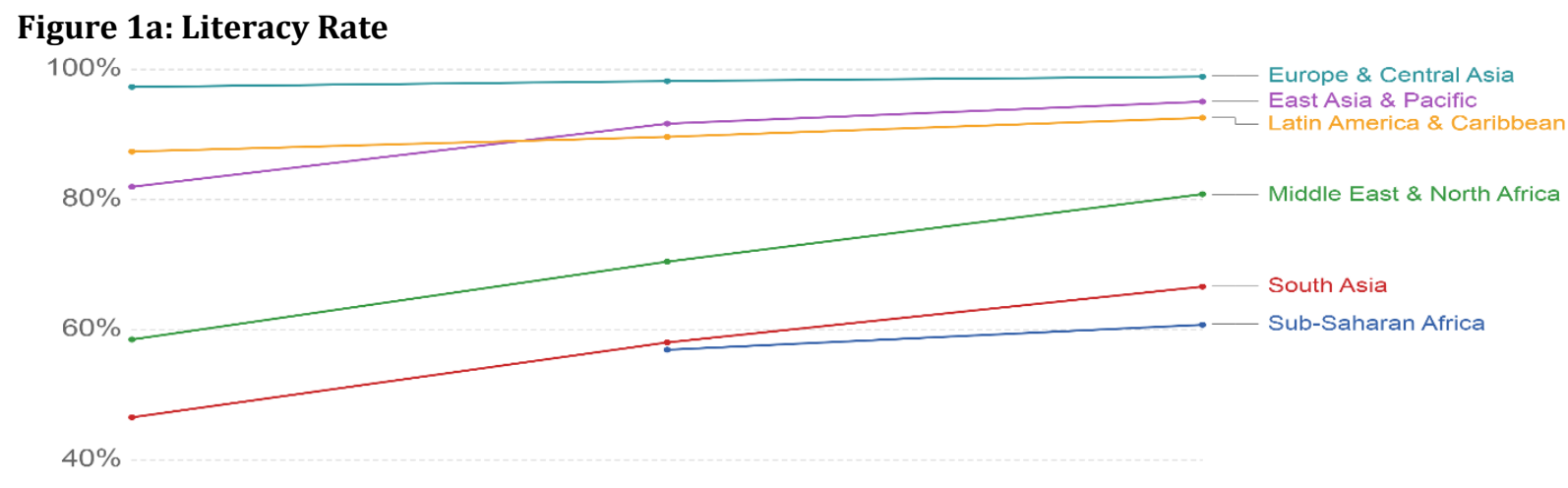

$20 \%$

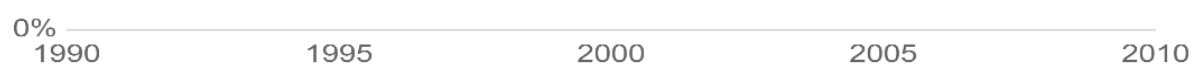

Source: unesdoc.unesco.org 
Figure 1b: Youth Literacy Rates

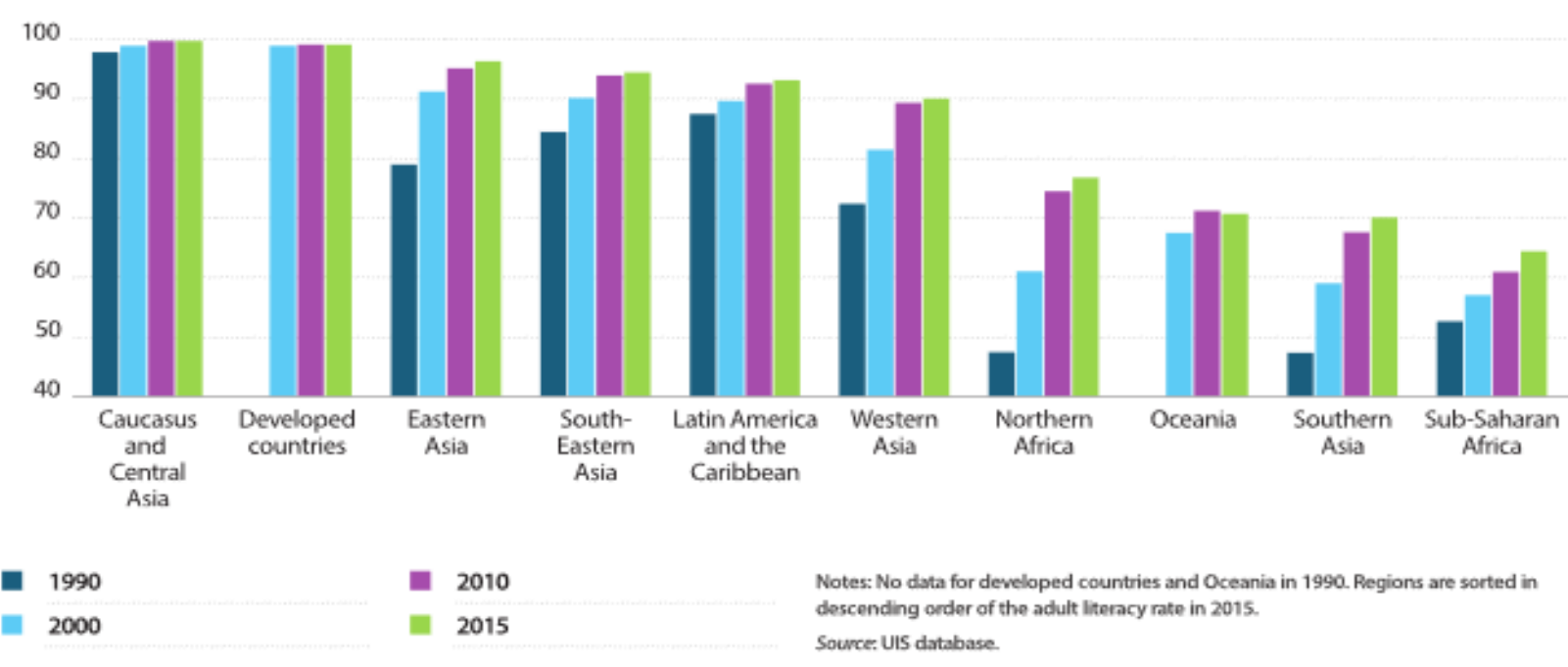

Source: unesdoc.unesco.org

Furthermore, several studies conducted have suggested that most governments neglect and are often not concerned with the increasing illiteracy among their populations especially with adult literacy. The pattern is evident between 1999 through 2015 where the number of literate people in the world has declined from 4.0 to 3.7 billion (Blunch, 2017). Kim (2018) observed discrepancies in literacy gaps within the framework of the United Nations Sustainable Development Goals. The results found significant intergenerational literacy gaps and several trends of literacy gaps across nations. These gaps are even more alarming when placed in the context of a global population. Within the same period, this number has jumped from six billion to roughly seven billion. The number of children studying today is a third lower than the same number in the 20th century. Women are less literate than men; a third of women in the world are illiterate and have never been to school, and only less than half have attended a secondary school. Among the latest projects and campaigns is the Adolescent Girls Initiative in Afghanistan, Emergency Youth Employment and Skills Development Project in sub-Sahara Africa, School Sector Reform Program in Nepal, to name a few amongst hundreds. The persistent theme to these various programs is that illiteracy is notwithstanding prevalent in the world and more study is still needed to eradicate it, thus our interest in this issue. Perhaps one of the major setbacks combating youth illiteracy is the discrimination that exists in educational opportunities based on a gender bias that is the focus of our study; to look at the differences in literacy rate between males and females (Olaniyan, 2008). As of 2015, the statistics indicate that the illiteracy rate between 2005-2015, Africa has the highest illiteracy rate of $35.7 \%$, while $30.1 \%$ for South Asia, $20 \%$ in Latin American and $20 \%$ for Middle East.

Figure 2: The Illiteracy Rate of Among Adults Over 15-Year-Olds from 2005-2015 by World Regions

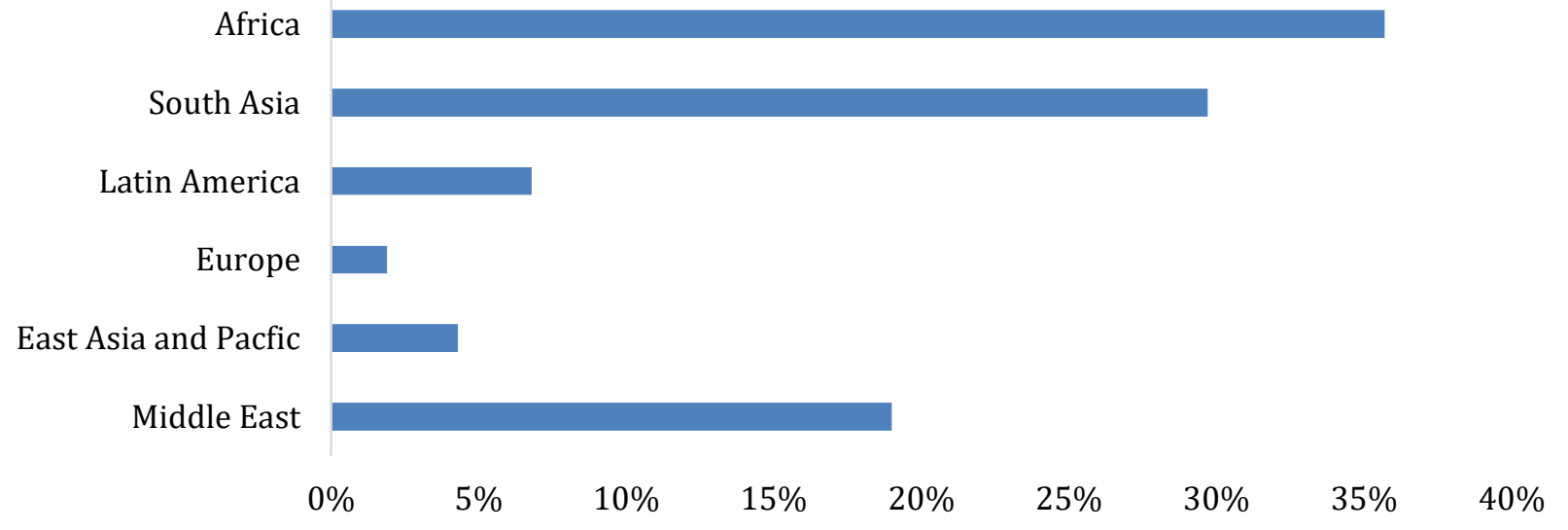


Therefore, the primary goal of this current study is to compare five major regions in the world as classified by the World Bank in regards to the differences which exist in literacy. Hence, this current research study would attempt to provide responses to these research questions: Is youth literacy rate as a fraction of between the age of 15 and 24 that are capable of comprehending, reading and writing for their everyday living is significant? Is there a significant gender difference in youth literacy among the world regions? Is there a significant difference in youth literacy among the world regions?

\section{Research Design}

By definition, the youth literacy rate is "the proportion of people between the age of 15 and 24 that are capable of comprehending, reading and writing for their everyday living. (The World Bank www Worldbank.org/projects), Similarly, Organization for Economic Co-operation and Development (OECD) in 2013 assessment data construct literacy as a multidimensional skill to be learned and measured." Therefore, the primary goal is to compare the literacy rate of males and females among five major regions in the world as classified by the World Bank. To study this variation, this research conducts a multivariate analysis of variance. Cleophas and Zwinderman (2018) noted that is the general technique for analyzing multivariate data but are restricted in the scope of variables that were included and owing to the weakness of associations among variables decreasing the statistical power of the test. In addition, complete statistics are missing and MANOVA of male literacy and female literacy (Yokozeki 1999). This research subscribed to MANOVA because we measure two IV's and by measuring two DVs rather than one, we believe we can improve the chance of figuring out how the regions different relative in literacy. MANOVA may also reveal differences not detected by separate MANOVAs. In this analysis, a multivariate F-value was used because the two measures are associated when carrying out the significance test. The following research hypotheses for the multivariate study are:

(1) $\mathbf{H}_{\mathbf{0}}$ : There is no significant difference in literacy rate among the five regions in the world.

$\mathbf{H}_{\mathbf{0}}: \mu_{1}=\mu_{2}=\mu_{3}=\mu_{4}=\mu_{5}$

(2) $\mathbf{H}_{\mathbf{0}}$ : There is no significant gender difference in youth literacy among the five world regions.

$\mathbf{H}_{\mathbf{0}}: \mu_{1}=\mu_{2}$

(3) $\mathbf{H}_{\mathbf{0}}$ : There is no significant interdependence between factors Country and Gender. All the main differences between treatment conditions are explained by the main effects of the two factors.

The subjects for the analysis are 50 countries randomly selected from five regions of the world. A sample of 10 countries from each region randomly selected for the analysis. The data source is The World Bank; yearly data in which countries are ranked countries based on progress in different areas including education. The dependent variable for the analysis is the youth literacy rate, for females and males (\% of females and males 15-24 age), one of the world development indicator data (www Worldbank.org/projects).

\section{Technical Report}

The distributional form of the data is illustrated in Figure 3. The boxplots illustrate wider spread than what has been claimed by the different organizations that have been involved in the study and discussion in Literacy in the world. Greatest difference between males and females among the five regions is seen mainly in the Middle East. The boxplots also illustrate the medians for males and females among the five regions that significantly measure out. The study presents a descriptive statistics of the data in Table 1 where the means and standard deviations of the countries for both dependent variables are categorized for the independent variable in the regions. The range is used to show some differences, however, as seen in box plot graph the most difference is evident in the Middle East. 
Table 1: Country 1 Dependent Variable: Male Literacy

\begin{tabular}{lll}
\hline Country & Mean & Std. Error \\
\hline Africa 1 & 81.825 & 11.572 \\
Middle East 2 & 92.685 & 5.836 \\
Europe 3 & 99.04 & 1.824 \\
Asia 4 & 87.867 & 11.655 \\
Latin America 5 & 96.298 & 9.637 \\
\hline
\end{tabular}

Table 2: Country 1 Dependent Variable: Female Literacy

\begin{tabular}{lll}
\hline Country & Mean & Std. Error \\
\hline Africa 1 & 80.760 & 15.693 \\
Middle East 2 & 90.095 & 12.471 \\
Europe 3 & 99.180 & 1.306 \\
Asia 4 & 86.808 & 12.454 \\
Latin America 5 & 96.654 & 4.763 \\
\hline
\end{tabular}

Multivariate Test: The research computes a multivariate test using Predictive Analytics Software (PASW). The output results show that the multivariate test is significant. Wilks' Lambda for school effect shows a significance value of .001 and $p<.05$. Therefore, there is enough evidence to conclude that literacy rates of male and female across the regions are different i.e. literacy rate of male and female is significantly affected by regions (Table 2).

Figure 3: Male and Female Literacies Comparison

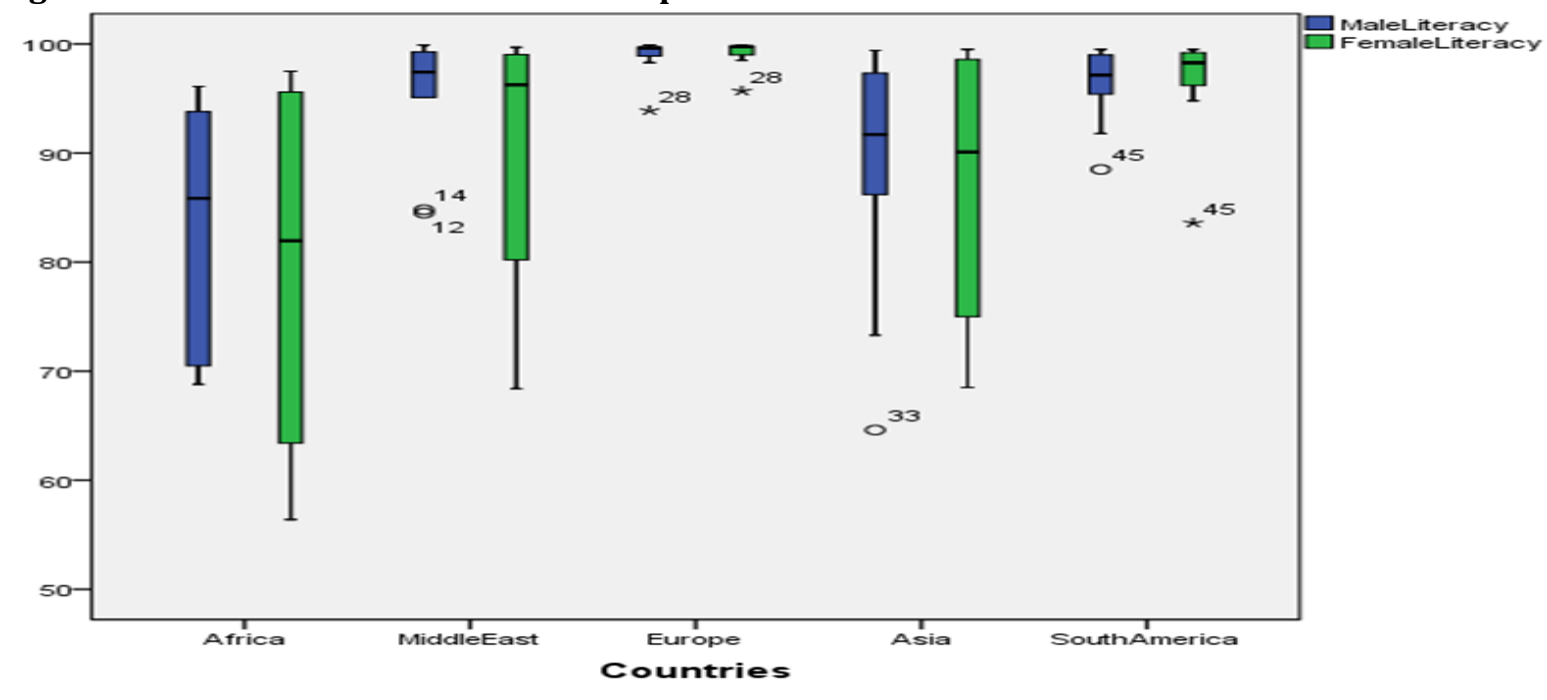

Table 3: Country 1 -Descriptive Statistics for Gender

\begin{tabular}{lllll}
\hline & & & \multicolumn{2}{c}{$\mathbf{9 5 \%}$ Confidence Interval } \\
\cline { 4 - 5 } Gender & Mean & Std. Error & Lower Bound & Upper Bound \\
\hline Male & 92 & 1 & 90 & 95 \\
Female & 91 & 1 & 88 & 93 \\
\hline
\end{tabular}

The results of the Multivariate Analysis of variance MANOVAs are presented in Table 3. Bonferroni $\alpha$ correction of .025 is used for each $t$-test to account of Multiple MANOVA's Country region has statistical significance on both male and female literacy (Hox, \& van de Schoot 2018, and Pituch \& Stevens 2016). 
Country region has a statistically significant effect on both male and female literacy. This study also includes MANOVAs with Tukey's HSD post-hoc tests, as shown in Table 4. The analysis suggests that gender disparity in education is still an issue among some countries in the world today, perhaps much more present in the Middle East than all other regions.

Table 4: Tests of Between-Subjects Effects for Literacy

\begin{tabular}{llllll}
\hline Source & Type III Sum of Squares & DF & Mean Square & F & Sig. \\
\hline Corrected Model & 3941.497 & 9 & 438 & 4.848 & .000 \\
Intercept & 838012.38 & 1 & 838012.38 & 9276.4 & .000 \\
Country & 3761.564 & 4 & 940.391 & 10.410 & .000 \\
Gender & 79 & 1 & 79.123 & .876 & .352 \\
Country* Gender & 101 & 4 & 25.202 & .279 & .891 \\
Error & 8130.35 & 90 & 90.337 & & \\
Total & 850084.24 & 100 & & & \\
Corrected Total & 12071.852 & 99 & & & \\
\hline
\end{tabular}

First, for the $\mathrm{H}_{0}$ : There is no significant difference in literacy rate among the five regions in the world.

$\mathrm{H}_{0}: \mu_{1}=\mu_{2}=\mu_{3}=\mu_{4}=\mu_{5}$

At 0.05 , level of significance this analysis was carried out. The result reveals that the constructed Multivariate Tests- Dependent Variable and there is a significant difference in literacy rate among the five regions in the world. The results on the Multivariate Analysis of variance (MANOVA) for the model are shown in Table 5. The results of Multivariate Tests- Dependent using Wil's Lambda test with ( $\mathrm{DF}=8, \mathrm{~F}=473.48 \mathrm{a}, \mathrm{P}<0.05$ ), indicated a statistically significant difference in literacy rate among the five regions in the world.

Table 5: Multivariate Tests- Dependent Variable: Countries

\begin{tabular}{lllllll}
\hline Effect & & Value & F & Hypothesis DF & Error & Sig. \\
\hline \multirow{2}{*}{ Intercept } & Pillai's Trace & 0.9994 & $3430.59^{\mathrm{a}}$ & 2.000 & 44.000 & 0.000 \\
& Wil's Lambda & 0.006 & $3430.59^{\mathrm{a}}$ & 2.000 & 44.000 & 0.000 \\
& Hotelling's Trace & 155.936 & $3430.59^{\mathrm{a}}$ & 2.000 & 44.000 & 0.000 \\
& Roy's Largest Root & 155.936 & $3430.59^{\mathrm{a}}$ & 2.000 & 44.000 & 0.000 \\
Countries & Pillai's Trace & 0.479 & $3.48 \mathrm{a}$ & 8.000 & 90.000 & 0.000 \\
& Wil's Lambda & 0.561 & $3.68^{\mathrm{a}}$ & 8.000 & 88.000 & 0.000 \\
& Hotelling's Trace & 0.709 & 3.81 & 8.000 & 86.000 & 0.000 \\
& Roy's Largest Root & 0.585 & $6.58^{\mathrm{b}}$ & 4.000 & 45.000 & 0.000 \\
\hline
\end{tabular}

Second, for the $\mathrm{H}_{0}$ : There is no significant gender difference in youth literacy among the five world regions. $\mathrm{H}_{0}: \mu_{1}=\mu_{2}$

For the null hypothesis a 0.05 level of significance, this analysis was carried out using Tests of BetweenSubjects Effects- Dependent Variable for Gender and Literacy. The analysis reveals that there is a significant difference in male literacy among the five regions in the world. The results on the MANOVA for the model are shown in Table 6 ( $D F=4, F=6.538, P<0.05$ ), indicated a statistically significant difference in Male Literacy among the five regions in the world. Also using a 0.05 level of significance this test result shows a significant difference in Female Literacy among the five regions in the world. The results on the MANOVA for the model are shown in Table 6 (DF $=4, F=4.699, \mathrm{P}<0.05)$, indicated a statistically significant difference in female literacy among the five regions in the world. 


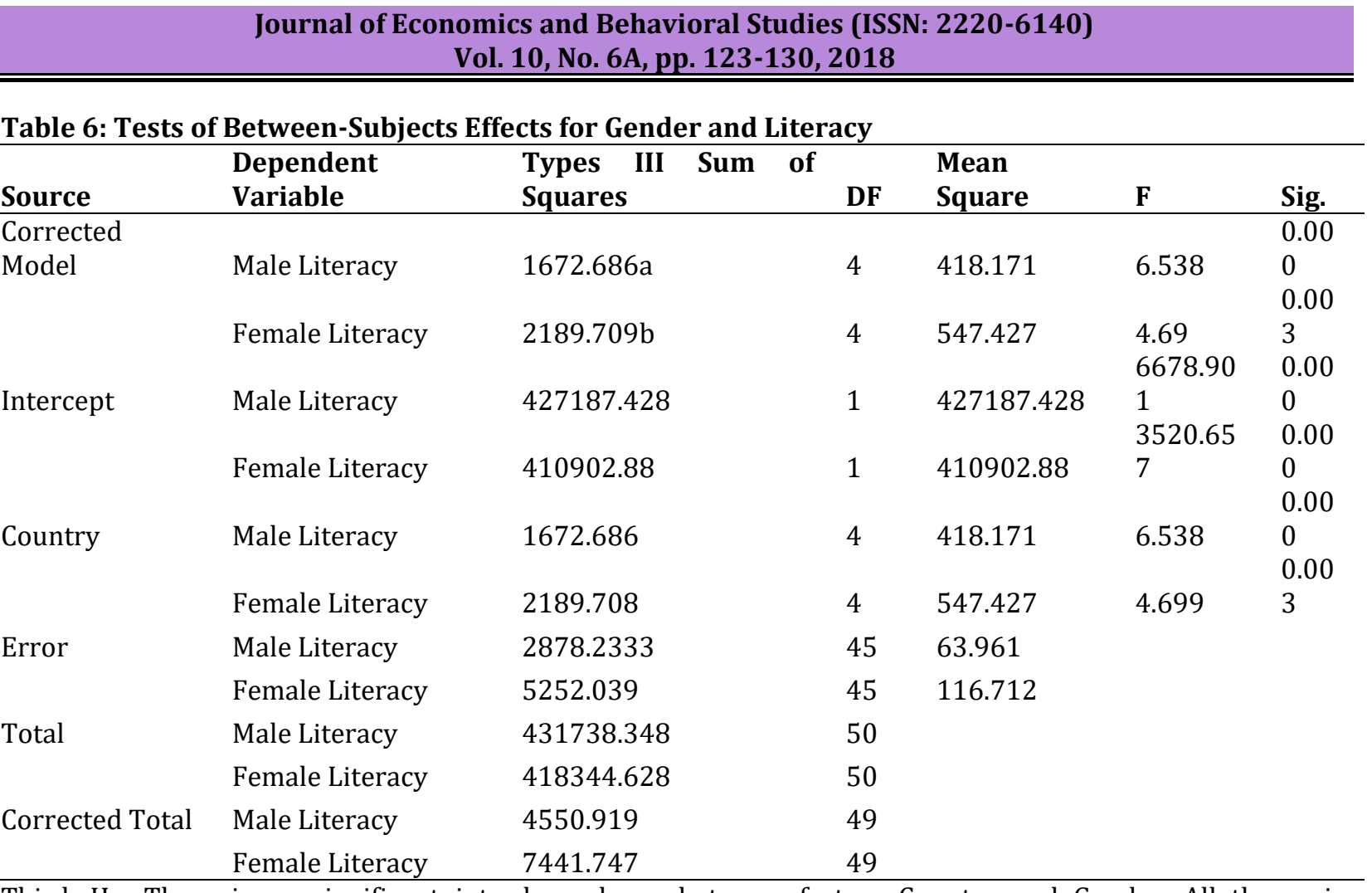

Third, $\mathrm{H}_{0}$ : There is no significant interdependence between factors Country and Gender. All the main differences between treatment conditions are explained by the main effects of the two factors

Male Literacy: For the null hypothesis a 0.05 level of significance, this analysis was carried out using Tests of Multiple Comparisons between Gender Literacy and Countries. First, when using male literacy as the dependent variable and Africa as a base country, the result indicates a significant difference in male literacy among five regions expect Asia Table 7. Second, with the Middle East as a base region, the result shows a no significant difference in male literacy among the regions in the world except for Africa Table 7. Third, with Europe as a base region, the result shows a no significant difference in male literacy among the five regions expect for Africa Table 7. Fourth, with Asia as a base region, the result indicates a no significant difference in male literacy among the five regions expect for Africa Table 7. Finally, with Latin America as a base region, the result shows a no significant difference in male literacy among the five regions expect for Africa Table 7.

Table 7: Tests of Multiple Comparisons: Gender Literacy and Countries

\begin{tabular}{llllll}
\hline Dependent Variable & (I)Country & (J)Country & Mean Difference(I-J) & Std. Error & Sig. \\
\hline Male Literacy & Africa & Middle East & $-12.3850^{*}$ & 3.57661 & 0.010 \\
& & Europe & $-16.0100^{*}$ & 3.57661 & 0.000 \\
& & Asia & -6.0340 & 3.57661 & 0.451 \\
& \multirow{4}{*}{ Middle East } & Latin America & $-13.2830^{*}$ & 3.57661 & 0.005 \\
& Africa & $12.3850^{*}$ & 3.57661 & 0.010 \\
& Europe & -3.6250 & 3.57661 & 0.848 \\
& Asia & 6.3510 & 3.57661 & 0.400 \\
& Europe & Latin America & -0.8980 & 3.57661 & 0.999 \\
& Africa & $16.0100^{*}$ & 3.57661 & 0.000 \\
& Middle East & 13.2830 & 3.57661 & 0.848 \\
& & Asia & 9.9760 & 3.57661 & 0.400 \\
& Asia & Latin America & 2.7270 & 3.57661 & 0.999 \\
& & Africa & 6.0340 & 3.57661 & 0.452 \\
\hline
\end{tabular}




\begin{tabular}{|c|c|c|c|c|c|}
\hline \multicolumn{6}{|c|}{$\begin{array}{l}\text { Journal of Economics and Behavioral Studies (ISSN: 2220-6140) } \\
\text { Vol. 10, No. 6A, pp. 123-130, } 2018 \\
\end{array}$} \\
\hline \multirow{27}{*}{ Female Literacy } & \multirow{7}{*}{ Latin America } & Europe & -6.3510 & 3.57661 & 0.400 \\
\hline & & Middle East & -9.9760 & 3.57661 & 0.057 \\
\hline & & Europe & -7.2490 & 3.57661 & 0.270 \\
\hline & & Africa & $13.2830^{*}$ & 3.57661 & 0.005 \\
\hline & & Middle East & 0.8980 & 3.57661 & 0.999 \\
\hline & & Europe & -2.7270 & 3.57661 & 0.940 \\
\hline & & Asia & 7.2490 & 3.57661 & 0.270 \\
\hline & \multirow[t]{2}{*}{ Africa } & Middle East & -9.3354 & 4.8314 & 0.316 \\
\hline & & Europe & -18.4200 & 4.8314 & 0.004 \\
\hline & \multirow{5}{*}{ Middle East } & Asia & -6.0486 & 4.8314 & 0.721 \\
\hline & & Latin America & $-15.6636^{*}$ & 4.8314 & 0.018 \\
\hline & & Africa & 9.3354 & 4.8314 & 0.316 \\
\hline & & Europe & -9.0846 & 4.8314 & 0.342 \\
\hline & & Asia & 3.2867 & 4.8314 & 0.960 \\
\hline & \multirow{4}{*}{ Europe } & Latin America & -6.3282 & 4.8314 & 0.687 \\
\hline & & Africa & $18.4200^{*}$ & 4.8314 & 0.004 \\
\hline & & Middle East & 9.0846 & 4.8314 & 0.342 \\
\hline & & Asia & 12.2714 & 4.8314 & 0.095 \\
\hline & \multirow{4}{*}{ Asia } & Latin America & 2.7564 & 4.8314 & 0.979 \\
\hline & & Africa & 6.0486 & 4.8314 & 0.721 \\
\hline & & Europe & -3.2867 & 4.8314 & 0.960 \\
\hline & & Middle East & -12.2714 & 4.8314 & 0.095 \\
\hline & \multirow{5}{*}{ Latin America } & Europe & -9.0846 & 4.8314 & 0.287 \\
\hline & & Africa & 15.6636 & 4.8314 & 0.018 \\
\hline & & Middle East & 6.3282 & 4.8314 & 0.687 \\
\hline & & Europe & -2.7564 & 4.8314 & 0.979 \\
\hline & & Asia & -9.0846 & 4.8314 & 0.287 \\
\hline
\end{tabular}

Female Literacy: For the null hypothesis a 0.05 level of significance, this analysis was carried out using Tests of Multiple Comparisons between Gender Literacy and Countries. First, when using female literacy as the dependent variable and Africa as a base country, the result shows a significant difference in female literacy among the regions in the world except Europe and Latin America Table 7. Second, with the Middle East as a base region, the result indicates a no significant difference in female literacy among the regions in the entire world (Table 7). Third, with Europe as a base region, the results also show a no significant difference in male literacy among the regions in the world except for Africa Table 7. Fourth, with Asia as a base region, the result indicates no significant difference in female literacy among the regions in the world except for Africa Table 7. Finally, with Latin America as a base region, the result shows a no significant difference in female literacy among the regions in the world except for Africa Table 7.

\section{Conclusion}

This current study suggests that there are countries that are still lagging behind in education. However, the gender gap has significantly reduced across. The findings of the results were examined vis-à-vis the study's research questions. The first research question is to assess youth literacy rate as the fraction people between the age of 15 and 24 that are able to read and write. With regard to this, the findings show the largest difference between males and females among the five regions is seen mainly in the Middle East. Hence, the study concludes that literacy rates of male and female across the regions are different for Youth literacy rate 


$\begin{array}{r}\text { Journal of Economics and Behavioral Studies (ISSN: 2220-6140) } \\ \text { Vol. 10, No. 6A, pp. 123-130, } 2018 \\ \hline \hline\end{array}$

is the fraction people between the age of 15 and 24. The second research questions identified and test whether there is a significant gender difference in youth literacy among the world regions. As illustrated as above and field observations of their activities, the analysis suggests that gender disparity in education is still an issue among some countries in the world today, perhaps much more present in the Middle East than all other regions. The conclusion is that there is a significant difference specifically in female Literacy among the five regions in the world. The third objective measured differences between factors Country and Gender. All the main differences between treatment conditions are explained by the main effects of the two factors. The overwhelming conclusion is that that there is a no significant difference in male literacy among the regions in the world except for Africa and specifically, there is no significant difference in female literacy among the regions in the world.

\section{References}

Blunch, N. (2017). Adult literacy programs in developing countries. IZA World of Labor 2017: 374 doi: 10.15185/izawol.374

Cleophas, T. J. \& Zwinderman, A. H. (2018). Multivariate Analysis of Variance and Canonical Regression. In: Regression Analysis in Medical Research. Springer, Cham.

Hox, J. J., Moerbeek, M. \& van de Schoot, R. (2018). Multilevel Analysis. New York: Routledge.

Max Roser and Esteban Ortiz-Ospina. (2018). Literacy Published online at our WorldInData.org. Retrieved from: 'https://ourworldindata.org/literacy

Nitya Rao \& Caroline Sweetman. (2014). Introduction to Gender and Education, Gender \& Development, 22(1), $1-12$.

Olaniyan, D. A. \& Okemakinde, T. (2008). Human Capital Theory: Implication for Education Development" European Journal of Scientific Research, 24(2), 157-162.

Organization for Economic Co-operation and Development. (2013a). OECD skills outlook 2013: First results from the survey of adult skills. Paris: OECD.

Pituch, K. A. \& Stevens, J. P. (2016). Applied multivariate statistics for the social sciences: Analyses with SAS and IBM's SPSS (6th ed). New York: Routledge.

Suehye Kim. (2018). Literacy skills gaps: A Cross-level analysis on International and Intergenerational Variations, International Review of Education, 64-85.

Yokozeki, Y. (1999). Gender in Education and Development, Journal of International Cooperation in Education, $1(1), 45-63$.

The UIS Global Education Digests (GED). (2006). The UNESCO EFA Global Monitoring Reports Literacy for Life. The UNDP Human Development Reports.

UNESCO. (2014). Skills for holistic human development. UNESCO Asia-Pacific Education Policy Brief, 2. 